\title{
Effect of periodontal disease on the bond strength of fiber post cemented with different adhesive systems and resin luting agents
}

Germana Coeli de Farias Sales ${ }^{1 *}$, Estela Santos Gusmão ${ }^{2}$, Rosenês Lima dos Santos ${ }^{1}$, Hugo Lemes Carlo ${ }^{3}$, Sílvio de Barros ${ }^{4}$ and Viviane Maria Gonçalves de Figueiredo ${ }^{1}$

\footnotetext{
* Correspondence: gcoeli@globo.com ${ }^{1}$ Federal University of Paraiba, Clinics and Preventive Dentistry

Department, Universidade Federal da Paraíba, Centro de Ciências da Saúde, Departamento de Clínica e Odontologia Social, Cidade Universitária, João Pessoa, PB, Brasil, 58051-900

Full list of author information is available at the end of the article
}

\begin{abstract}
The objective of the present study was to determine the effect periodontal disease on the bond strength of fiberglass posts, different adhesive systems and resin cements. Ninety human maxillary central incisors roots extracted due to periodontal disease or prosthetic reasons were endodontically treated and divided into six experimental groups: NPD-ARC - no periodontal disease/RelyX ARC and Adper Single Bond 2; NPD-PF - no periodontal disease/Panavia F and ED Primer; NPD-U - no periodontal disease/RelyX U100; PD-ARC - periodontal disease/RelyX ARC and Adper Single Bond 2; PD-PF - periodontal disease/Panavia F and ED Primer; and PD-U - periodontal disease/RelyX U100. Specimens were subjected to push-out test and data were analyzed by two-way ANOVA and Tukey's test ( $p=0.05)$. The periodontal disease groups showed that the Panavia F/ED Primer group presented no significantly higher mean values compared with RelyX U100, and that both presented significantly higher mean values when compared with RelyX ARC/Single Bond 2 group. These results were also observed in roots with no periodontal disease. There were no differences in bond strength mean values of roots related or not to periodontal disease.
\end{abstract}

Keywords: Resin cements; Primers and coupling agents; Periodontitis; Post and core technique; Tooth root

\section{Background}

A persistent problem in clinical dentistry is associated with fractures occurring in endodontically treated teeth [1]. Restoration of these teeth, in some cases, can be a complicated process because of extensive structural defects resulting from caries, cavity access and the excessive removal of radicular dentin during endodontic treatment [2-4]. The Restoration must restore the form and function of the tooth, create resources for restorative material anchorage to prevent it from being displaced and provide adequate distribution of forces $[2,5]$.

Numerous restoration techniques for endodontically treated teeth have been advocated with criteria for success dependent upon variations in length, diameter, shape and surface configuration, quantity of dentinal structure, and materials and techniques used in reconstruction [6-8]. Teeth with a minimal or moderate degree of destruction

\section{Springer}

(C) 2014 Sales et al.; licensee Springer. This is an open access article distributed under the terms of the Creative Commons Attribution License (http://creativecommons.org/licenses/by/2.0), which permits unrestricted use, distribution, and reproduction in any medium, provided the original work is properly cited. 
can be restored conservatively with bonded direct composite restorations $[9,10]$. In cases where most of the coronal portion is lost, a common method to restore such teeth is the use of a post, onto which a full crown is cemented $[5,6,10]$. The post functions primarily to aid the retention of the restoration and to protect the tooth by dissipating or distributing forces along the tooth [11].

Posts can be divided into two categories: (1) custom/cast post-and-core and (2) prefabricated posts, primarily with composite core. Metal alloys are generally used to fabricate post-and-core [3,6]. Prefabricated posts are divided into two groups: (1) metallic, such as titanium, palladium, gold and stainless steel alloy posts, and (2) non-metallic, such as carbon fiber, glass fiber and yttrium-stabilized zirconia-based ceramic posts $[3,6,12,13]$.

Various luting agents and the corresponding adhesive systems have been proposed for bonding non-metallic posts to root canal dentin. These materials can be divided into etch-and-rinse adhesives, self-etching adhesives and self-adhesive resin cements, which does not require any pre-treatment of dentin [2,14-16]. The etch-and-rinse system involves the use of an acid, which removes the smear layer and demineralizes the dentine to a depth of several microns. The acid is rinsed off using water and then a primer and an adhesive resin are applied $[17,18]$. Self-etch adhesives however, use a self-etching primer to promote condition and prime the dentine. This is followed by the application of an adhesive resin $[17,18]$. Simplified versions of both adhesives have made bonding simpler, faster, and more user-friendly $[18,19]$. In an attempt to simplify procedures, a new group of resin cements have been introduced. These products are self-adhesive, including acidic and hydrophilic monomers in their composition, which simultaneously demineralize and infiltrate in the dentin. Therefore, they require no conditioning or priming pretreatments of the substrate $[2,16,18,20]$.

Periodontal disease is a heterogeneous group of disorders affecting the periodontium, the most common are gingivitis and chronic periodontitis. Substantial evidence indicates that susceptibility to periodontal disease varies among patients and is a function of both acquired and intrinsic risk factors [21-23]. Periodontitis is an irreversible periodontal attachment loss - destruction of periodontal ligament and/ or alveolar bone - in some patients [24]. The causal agents of periodontal disease may be appointed as local and systemic factors. Local factors typically include, but are not limited to, dental plaque, gingival inflammation, prior attachment loss, furcations, pocket formation, occlusal trauma and defective restorations. Systemic factors include conditions that result in suppression of the immune system, alterations in endocrine status, and certain medications that specifically affect the gingiva. In addition, specific genetic markers have been linked to susceptibility to periodontitis [21,24-26]

It is supposed that loss of cementum and dentine structure may increase root permeability to periodontum space components [27], what should compromise the bond strength of the luting agents proposed for bonding posts to root canal dentin. The aim of the present study was to evaluate the influence of periodontal disease on the bond strength of a fiberglass post cemented with different adhesive systems and resin luting agents. The null hypothesis tested was that periodontitis has no influence on bond strength of fiber post and resin cements. 
Table 1 Materials tested - Commercial brand names, manufacturer and composition*

\begin{tabular}{|c|c|c|}
\hline Commercial brand name & Composition & Manufacturer \\
\hline RelyX ARC & $\begin{array}{l}\text { Silane treated ceramic. Silane treated silica. } \\
\text { TEGDMA. BISGMA. Functionalized dimethacrylate } \\
\text { polymer. Triphenylantimony. }\end{array}$ & 3 M/ESPE - St.Paul, Mn, USA \\
\hline Adper Single Bond 2 & $\begin{array}{l}\text { Silane treated silica (nanofiller). Bis-GMA. HEMA. } \\
\text { Dimethacrylate. Methacrylate functional copolymer } \\
\text { of polyacrylic and polytaconic acid. Water. } \\
\text { Ethyl alcohol. }\end{array}$ & 3 M/ESPE - St.Paul, Mn, USA \\
\hline Adper Scotchbond - Etching & $\begin{array}{l}35 \% \text { - phosphoric acid. Thickener (pyrogenic silica). } \\
\text { Water-soluble surfactant, (pH 0.6). }\end{array}$ & 3 M/ESPE - St.Paul, Mn, USA \\
\hline \multirow[t]{2}{*}{ Panavia F 2.0} & $\begin{array}{l}\text { Paste A: 10-Methacryloyloxydecyl dihydrogen } \\
\text { phosphate. Hydrophobic aromatic dimethacrylate. } \\
\text { Hydrophobic aliphatic methacrylate. Hydrophilic } \\
\text { aliphatic dimethacrylate. Silanated silica filler. } \\
\text { Silanated colloidal sílica. dl-Camphorquinone. } \\
\text { Catalysts. Initiators. }\end{array}$ & Kuraray Medical/Okayama-Japan \\
\hline & $\begin{array}{l}\text { Paste B: Hydrophobic aromatic dimethacrylate. } \\
\text { Hydrophobic aliphatic methacrylate. Hydrophilic } \\
\text { aliphatic dimethacrylate. Silanated barium glass } \\
\text { filler. Catalysts. Accelerators. Pigments. }\end{array}$ & \\
\hline \multirow[t]{2}{*}{ ED Primer } & $\begin{array}{l}\text { Liquid A: 10-Methacryloyloxydecyl dihydrogen } \\
\text { phosphate. N-Methacryloyl-5-aminosalicylic acid. } \\
\text { Water. Accelerators. }\end{array}$ & Kuraray Medical/Okayama-Japan, \\
\hline & $\begin{array}{l}\text { Liquid B: N-Methacryloyl-5-aminosalicylic acid. } \\
\text { Water. Catalysts. Accelerators. }\end{array}$ & \\
\hline \multirow[t]{2}{*}{ RelyX U100 } & $\begin{array}{l}\text { Base paste: glass powder. TEGDMA. Silane treatead } \\
\text { silica. Sodium persulfate. }\end{array}$ & 3 M ESPE/Seefeld-Germany \\
\hline & $\begin{array}{l}\text { Catalyst paste: glass powder. Substituted } \\
\text { dimethacrylate. Silane treatead silica. Sodium } \\
\text { P-toluenesulfinate. Calcium hydroxide. }\end{array}$ & \\
\hline Reforpost & Epoxi resin. Initiators. Stabilizers. Glass fibers. & Ângelus - Londrina, PR, Brazil \\
\hline Silano & $\begin{array}{l}\text { 90\%-Ethyl alcohol. 10\%- } \\
\text { 3-Methacryloxypropyltrimethoxysilane. Water. }\end{array}$ & Ângelus - Londrina, PR, Brazil \\
\hline
\end{tabular}

${ }^{*}$ According to manufacturer's information.

\section{Methods}

Commercial brand names, chemical composition and material manufacturers are presented in Table 1. The push-out bond strength test was carried out and the experimental design of the study is showed in Figure 1.

Ninety intact human maxillary central incisors with similar root lengths $(14 \mathrm{~mm})$ were selected. Only teeth indicated to extraction due to periodontal disease and/or prosthetic purposes were collected. The specimens were refrigerated in a solution of
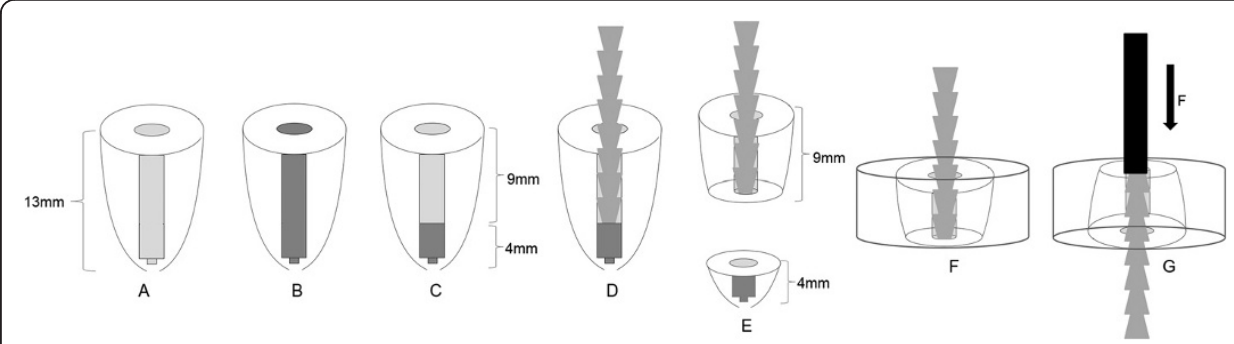

Figure 1 Experimental design of the study. (A) Removal of the tooth root - $13 \mathrm{~mm}$ length; (B) endodontic treatment executed; (C) preparation of the root canal for post insertion - $9 \mathrm{~mm}$ depth; (D) glass fiber post cementation using different adhesive systems and resin cements; (E) root section - 9 mm length; (F) root fragment embedded in acrylic resin; (G) push-out test. 
0.9\% sodium chloride and 0.1\% thymol (LabSynth Produtos para Laboratórios Ltda., Diadema, SP, Brazil) for no longer than three months after extraction. They were cleaned of gross debris and placed in distilled water for twenty-four hours before beginning the experiment. The teeth used in this study were obtained under Protocol No. 83/06/07, which was analyzed and approved by the Research Ethics Committee, Health Sciences Center, Federal University of Paraiba.

All teeth were checked at $40 \times$ magnification and X-rays images. Those presenting caries, cracks, irregularities, anatomic abnormalities, internal or external reabsorptions, calcifications, incomplete formation, root curvature and previous endodontic treatment were eliminated. They were distributed into two groups considering the indication to extraction due to periodontal disease (45 teeth) and prosthetic purposes without periodontal disease (45 teeth).

The crown of each tooth was removed perpendicular to the long axis of the tooth using a flexible diamond disc at low speed (n.7020 - KG Sorensen, Barueri, SP, Brazil) and under water cooling. All roots were cut to a length of $13 \mathrm{~mm}$ (Figure 1A).

For endodontic treatment, a step-back preparation technique was used with stainless steel K-files and \#2 and \#3 Gates-Glidden burs (Dentsply Maillefer, York, PA, USA). All enlargement procedures were followed by irrigation with $2.5 \%$ sodium hypochlorite. Smear layer removal was done using 17\% ethylenediaminetetraacetic acid (EDTA) (Biodinâmica, Ibiporã, PR, Brazil). Final irrigation was performed with distilled water. Prepared root canals were then filled with gutta-percha cones using the lateral condensation technique and Sealer 26 (calcium hydroxide-resin sealer - Dentsply, York, PA, USA) -Figure 1B. The canal access was sealed with a temporary restorative material and subsequently, the filled roots were stored in distilled water at $37^{\circ} \mathrm{C}$ for $48 \mathrm{~h}$.

After storage, root canals were prepared to ensure a standardized space for post insertion. The canal space of each root was enlarged with a \#4 Largo drill (Dentsply Maillefer, York, PA, USA), providing access for a \#2 post, using a low-speed handpiece, to a depth of $9 \mathrm{~mm}$. During preparation of the canal, $3 \mathrm{~mm}$ of the endodontic filling was left at the apex of each canal (Figure 1C). The roots were randomly divided into six experimental groups $(n=15)$. A fiberglass post ( $\# 2$ Reforpost - Angelus, Londrina, PR, Brazil) and different resin cement systems were utilized in each group (Table 1):

- No periodontal disease/RelyX ARC and Adper Single Bond 2/post;

- No periodontal disease/Panavia F and ED Primer/post;

- No periodontal disease/RelyX U100/post;

- Periodontal disease/RelyX ARC and Adper Single Bond 2/post;

- Periodontal disease/Panavia F and ED Primer/post;

- Periodontal disease/RelyX U100/post.

The post was tried-in to the prepared post-space. Before post insertion, each post was cleaned with ethanol ( $70 \% \mathrm{vol}$.) for $30 \mathrm{~s}$, thoroughly air-dried and coated with a silane coupling agent (Silano - Angelus, Londrina, PR, Brazil). Posts were not manipulated until the luting procedure to avoid contamination of the post surface. In order to ensure the parallelism of the post during the lutting process it was used a metallic matrix. 
For the RelyX ARC cement groups, the roots were etched with 37\% phosphoric acid (Adper Scotchbond Etching - $3 \mathrm{M} / \mathrm{ESPE}$ - St. Paul, Mn, USA) for $15 \mathrm{~s}$ and waterrinsed. Then the excess water was removed using absorbent paper, leaving a moist dentin surface. The adhesive system, Adper Single Bond 2 (3 M/ESPE - St. Paul, Mn, USA), was applied using two consecutive coats, gentle air-dried for $5 \mathrm{~s}$, and light cured for $10 \mathrm{~s}$ with a halogen light (Optilux - Kerr Dental, Orange, CA, USA), with an intensity of $600 \mathrm{~mW} / \mathrm{cm}^{2}$, measured with the SDS radiometer (Kerr Dental, Orange, CA, USA). The RelyX ARC ( $3 \mathrm{M} / \mathrm{ESPE}$ ) base and catalyst paste were hand-mixed for $10 \mathrm{~s}$ and then inserted into the post space. The post was immediately inserted into the post space. Excess cement was removed and light-cured for $80 \mathrm{~s}$.

For the Panavia F groups, self-etching and self-curing Primers A and B (ED Primer Kuraray Medical, Okayama, Japan) were mixed and applied into the root canal for $60 \mathrm{~s}$ and dried with absorbent paper. The base and the catalyst pastes of the cement (Panavia F 2.0 - Kuraray Medical, Okayama, Japan) were then mixed in a 1:1 volume ratio during $10 \mathrm{~s}$, and the same cementation procedure was performed.

For the RelyX U100 cement groups, dentin pretreatment was not necessary. The RelyX U100 cement ( 3 M/ESPE, Seefeld, Germany) base paste and the catalyst paste were hand-mixed during $10 \mathrm{~s}$, and the same cementation procedure was performed.

Once the luting procedure was finished, specimens were stored in distilled water for $24 \mathrm{~h}$ at $37^{\circ} \mathrm{C}$ (Figure 1D). After the storage period, specimens were sectioned using a flexible diamond disc at low speed (n.7020 - KG Sorensen, Barueri, SP, Brazil) under water cooling. All roots were cut to a length of $9 \mathrm{~mm}$ (Figure 1E) and embedded in acrylic resin (Vipi, Pirassununga, SP, Brazil) - Figure 1F. Each specimen was marked with a dot on its coronal side and with the sample number on its apical side.

Push-out tests (Figure 1G) were performed with a universal testing machine (model AG-IC, Shimadzu, Kyoto, Japan) at a crosshead speed of $0.5 \mathrm{~mm} / \mathrm{min}$. All test specimens were loaded until fracture. To express bond strength in MPA (BS), the load value recorded (F) in Newton was divided by the area of the bonded interface:

$$
\mathrm{BS}=\mathrm{F} / 2 \pi \mathrm{rh}
$$

Where $\pi$ is the constant $3.14, \mathrm{r}$ is the post radius, and $\mathrm{h}$ is the specimen thickness in millimeters.

Bond strength data were submitted to statistical analysis. Two-way Analysis of Variance and Tukey's Test $(p=0.05)$ were used to analyze data of different cements whether or not related to periodontal disease. t-Student's Test were used to determine differences related or not to periodontal disease of one single cement $(p=0.05)$.

\section{Results}

Table 2 shows the mean push-out bond strengths and standard deviations for the experimental groups. Two-way ANOVA revealed significant difference $(p<0,001)$ of the

Table 2 Mean bond strength values in MPa ( \pm standard deviation) and Tukey Post-hoc*

\begin{tabular}{|c|c|c|c|}
\hline & RelyX ARC & Panavia & RelyX U100 \\
\hline No periodontal disease & $10.42^{B}( \pm 3,50)$ & $21.01^{\mathrm{A}}( \pm 4,90)$ & $17.04^{\mathrm{A}}( \pm 6,12)$ \\
\hline Periodontal disease & $11.55^{B}( \pm 5,52)$ & $20.66^{\mathrm{A}}( \pm 3,89)$ & $16.90^{\mathrm{A}}( \pm 5,31)$ \\
\hline
\end{tabular}


cements used on roots associated with periodontal disease or not. The mean values of the periodontal disease groups showed that the Panavia F/ED Primer group presented no significantly higher mean values compared with RelyX U100, and that both presented significantly higher mean values when compared with RelyX ARC/Single Bond 2 group. These results were also observed in the roots with no periodontal disease.

\section{Discussion}

The present study evaluated the influence of periodontal disease on the push-out bond strength of resin cements to root dentin. Different resin cements with different application protocols were analyzed. There were no differences in bond strength mean values of cements used in roots related or not to periodontal disease. Therefore, the main hypothesis of the present study was accepted.

Endodontically-treated teeth present different responses to mechanical loads from intact teeth. The removal of pulp and root dentin diminishes a protective feedback mechanism and reduces the stress-strain capacity of the teeth, compromising the root fracture resistance $[4,28]$. The stability of the teeth is reduced by endodontic preparative procedures, leading to more root deformations and less stiffness [29,30]. The success of restoration techniques for endodontically treated teeth is dependent upon variations in length, diameter and shape of a post. Quantity of dentinal structure, and materials and techniques used in the reconstruction are also important $[4,7,8,31]$. It is accepted that posts do not reinforce endodontically treated teeth. The placement of posts reduces the stress in the cervical area by directing along the post length the occlusion stress of the mouth $[1,4,11,31]$. Moreover, posts should be used when there is a need to provide additional retention for the core build-up $[8,10,13]$.

Post debonding is one of the most unfavorable situations for post-restored teeth and the use of different resin cements can influence the results [6,32,33]. A prerequisite for the use of fiber posts is their adhesive cementation, which creates a bond between the post and the root canal dentin and form a structurally and mechanically homogeneous complex. The combination of an adhesive bond to the root canal dentin with a resin core build-up allows the restoration of nonvital teeth while preserving the remaining tooth structure $[3,11,13]$. However, the goal is not only to achieve a high retentive bond strength of the fiber post, but also to avoid any microbiologic leakage along the root canal or post and to avoid degradation of the fiber post structure [34]. The purpose of the push-out test applied to the specimens in this study was to cause fracture of the dentin/cement and cement/post interface. This occurs because the cement has a lower elasticity modulus than the root dentin and the fiber post, creating a location of high stress concentration [2].

Due to the variability of the substrate, bonding to intra-radicular dentin has been considered a challenge and a variety of cements and corresponding adhesive systems may be proposed for bonding fiber posts to root canal dentine. Micromechanical adhesion of "etch-and-rinse" and "self-etch" adhesive systems is assumed to be the prime bonding mechanism. This is achieved by an exchange process by which inorganic tooth material is replaced by resin monomers that become interlocked in the exposed collagen of dentin [35]. As a consequence, adequately removing the smear layer together with demineralizing dentin to a small extent, good wetting, diffusion, penetration and 
good polymerization of the resin components are all important [35]. The self-adhesive resin cement has a bonding mechanism based on micromechanical retention and chemical adhesion. The cement contains multifunctional hydrophilic monomers with phosphoric acid groups which can react with hydroxyapatite and also infiltrate and modify the smear layer. The chemical interaction between the acidic monomers and hydroxyapatite ensures its adhesion to dentin [36,37].

The Panavia F cement presented no significantly higher mean values compared with RelyX U100 cement, and both presented significantly higher mean values when compared with RelyX ARC/Single Bond 2 group. Simplified adhesive systems (two step etch-and-rinse) are incompatible with self-cured and dual-cured resin cements. This may occur by the presence of acid resin monomers in the non-polymerized adhesive residual layer caused by oxygen inhibition, which react with the tertiary amine of the resin cement. Moreover, these adhesives promote a permeable hybrid layer, allowing water diffusion from the dentin and forming water droplets along the adhesive resincement interface $[2,38]$. The major concern with the self-etching primers is their efficacy in infiltrating thick smear layers such as those produced during post space preparations. Furthermore, the chemical polymerization of the adhesive may inhibit the nonpolymerized adhesive residual layer caused by oxygen [16]. The recently introduced self-adhering resin cements represent a promising new and simple luting strategy for bonding fiber posts to root canal dentine. The cement has an adequate interaction with dentin, because of the close relationship between the calcium ions of the dentin with the fixing agent of the cement. This interaction starts during mixing process, when the acid is partially neutralized by the hydroxyl released from the breakdown of calcium hydroxide during the reaction, or by water present in dentin. This reaction releases the phosphate group that is responsible for the tooth bonding to calcium [15,39].

Tooth affected by periodontal disease presents exposure of root dentin by gingival recession, periodontal pocket or scaling therapy. These complications may promote loss of cementum and dentine structure, increasing dental permeability to bacteria, as well as fluid movement between the pulp cavity and periodontium $[27,40]$. There is an inverse relationship between bond strength and permeability. It was observed that bond strength may be higher when permeability is low and it may be smaller when permeability is high [41]. Fortunately, it was not observed differences in bond strength mean values of roots related or not to periodontal disease but periodontal destruction is frequently observed in endodontically treated teeth. A retrospective study showed that periodontal problems constituted $32 \%$ of the failures of post-endodontic teeth, which was higher than the $8.6 \%$ of failures due to endodontic causes [42]. The impact of the periodontal status on the survival of endodontically treated teeth was observed $[43,44]$. As the height and density of the alveolar bone changes, tooth mobility increases due to the reduced support, altered centers of resistance and the associated increased moment of force [30]. A finite element study suggested that dentin stresses were 4-10 times higher than in teeth with normal bone height when the bone height is $6 \mathrm{~mm}$ below the cemento-enamel junction [45]. Bone loss may lower the fracture resistance of postrestored teeth, mostly due to increased root stress near the post apex and the cervical root portion $[43,44]$.

The retention of fiber posts in roots is dependent upon the adhesion between the resin cement and the dentin, as well as on the adhesion between the resin cement and 
posts, but the adhesion between resin and dentin is considered to be a weak point in luting a fiber post. In the present study, different cements with different adhesive methods influenced on the push-out bond strength of fiber post tested. The self-etch adhesive system in combination to Panavia F and the self-adhesive cement presented significantly higher mean values when compared with the etch-and-rinse adhesive and RelyX ARC. There were no differences in bond strength mean values of roots related or not to periodontal disease. Consequently, it is possible to assume that periodontal disease may not influence fiber posts cementation.

\section{Conclusion}

According to the results of the present study, it was possible to conclude that periodontal disease did not affected the bond strength mean values of fiber posts cementation. Adhesive system and resin cement significantly affected the push-out bond strength values.

\section{Competing interests}

The authors declare that they have no competing interests.

\section{Authors' contributions}

GCFS participated in the study design development, laboratory analysis, literature review, and in the writing of the manuscript. ESG participated in the design development, in the writing of the manuscript and is the coordinator. RLS participated in the design development and in the writing of the manuscript. HLC participated in the writing of the manuscript and did the manuscript final review. SB participated in the study design development, laboratory analysis and did the manuscript final review. VMGF participated in the writing of the manuscript. All the authors have read and approved the final manuscript.

\section{Author details}

${ }^{1}$ Federal University of Paraiba, Clinics and Preventive Dentistry Department, Universidade Federal da Paraíba, Centro de Ciências da Saúde, Departamento de Clínica e Odontologia Social, Cidade Universitária, João Pessoa, PB, Brasil, $58051-900$. 2University of Pernambuco, School of Dentistry, Universidade de Pernambuco, Faculdade de Odontologia, Av. General Newton Cavalcanti, n.1650, Tabatinga, Camaragibe, PE, Brasil, 54753-220. ${ }^{3}$ Federal University of Paraiba, Operative Dentistry Department, Universidade Federal da Paraíba, Centro de Ciências da Saúde, Departamento de Odontologia Restauradora, Cidade Universitária, João Pessoa, PB, Brasil, 58051-900. ${ }^{4}$ Federal Center of Technological Education in Rio de Janeiro, Centro Federal de Educação Tecnológica Celso Suckow da Fonseca, Laboratório de Compósitos e Adesivos, Av. Maracanã, 229 Bloco E - 50 andar, Rio de janeiro, RJ, Brasil, 20271-110.

Received: 3 September 2013 Accepted: 6 February 2014

Published: 25 Mar 2014

\section{References}

1. de Oliveira JA, Pereira JR, Lins do Valle A, Zogheib LV (2008) Fracture resistance of endodontically treated teeth with different heights of crown ferrule restored with prefabricated carbon fiber post and composite resin core by intermittent loading. Oral Surg Oral Med Oral Pathol Oral Radiol Endod 106(5):e52-57

2. Farina AP, Cecchin D, Garcia Lda F, Naves LZ, Pires-de-Souza Fde C (2011) Bond strength of fibre glass and carbon fibre posts to the root canal walls using different resin cements. Aust Endod J 37(2):44-50

3. Toksavul S, Zor M, Toman M, Gungor MA, Nergiz I, Artunc C (2006) Analysis of dentinal stress distribution of maxillary central incisors subjected to various post-and-core applications. Oper Dent 31(1):89-96

4. Makade CS, Meshram GK, Warhadpande M, Patil PG (2011) A comparative evaluation of fracture resistance of endodontically treated teeth restored with different post core systems - an in-vitro study. J Adv Prosthodont 3(2):90-95

5. Iglesia-Puig MA, Arellano-Cabornero A (2004) Fiber-reinforced post and core adapted to a previous metal ceramic crown. J Prosthet Dent 91(2):191-194

6. Soares CJ, Valdivia AD, da Silva GR, Santana FR, Menezes Mde S (2012) Longitudinal clinical evaluation of post systems: a literature review. Braz Dent J 23(2):135-740

7. Fernandes AS, Shetty S, Coutinho I (2003) Factors determining post selection: a literature review. J Prosthet Dent 90(6):556-562

8. Torbjorner A, Fransson B (2004) A literature review on the prosthetic treatment of structurally compromised teeth Int J Prosthodont 17(3):369-376

9. Mannocci F, Bertelli E, Sherriff M, Watson TF, Ford TR (2002) Three-year clinical comparison of survival of endodontically treated teeth restored with either full cast coverage or with direct composite restoration. J Prosthet Dent 88(3):297-301

10. Cheung W (2005) A review of the management of endodontically treated teeth. Post, core and the final restoration. J Am Dent Assoc 136(5):611-619

11. Asmussen E, Peutzfeldt A, Sahafi A (2005) Finite element analysis of stresses in endodontically treated, dowelrestored teeth. J Prosthet Dent 94(4):321-329 
12. Ozkurt Z, Iseri U, Kazazoglu E (2010) Zirconia ceramic post systems: a literature review and a case report. Dent Mater J 29(3):233-245

13. Binus S, Koch A, Petschelt A, Berthold C (2013) Restoration of endodontically treated teeth with major hard tissue loss bond strength of conventionally and adhesively luted fiber-reinforced composite posts. Dent Traumatol 29(5):339-354

14. Bitter K, Meyer-Lueckel H, Priehn K, Kanjuparambil JP, Neumann K, Kielbassa AM (2006) Effects of luting agent and thermocycling on bond strengths to root canal dentine. Int Endod J 39(10):809-818

15. De Munck J, Vargas M, Van Landuyt K, Hikita K, Lambrechts P, Van Meerbeek B (2004) Bonding of an autoadhesive luting material to enamel and dentin. Dent Mater 20(10):963-971

16. Erdemir U, Sar-Sancakli H, Yildiz E, Ozel S, Batur B (2011) An in vitro comparison of different adhesive strategies on the micro push-out bond strength of a glass fiber post. Med Oral Patol Oral Cir Bucal 16(4):e626-634

17. Foxton RM, Nakajima M, Tagami J, Miura H (2003) Bonding of photo and dual-cure adhesives to root canal dentin Oper Dent 28(5):543-551

18. Monticelli F, Ferrari M, Toledano M (2008) Cement system and surface treatment selection for fiber post luting. Med Oral Patol Oral Cir Bucal 13(3):E214-221

19. Peumans M, Kanumilli P, De Munck J, Van Landuyt K, Lambrechts P, Van Meerbeek B (2005) Clinical effectiveness of contemporary adhesives: a systematic review of current clinical trials. Dent Mater 21(9):864-881

20. Tamam E, Keskin S, Üçtașli MB (2010) Microtensile bond strength of self-adhesive resin-based dental cement to bleached enamel. J Adh 86(2):244-255

21. Kye W, Davidson R, Martin J, Engebretson S (2012) Current status of periodontal risk assessment. J Evid Based Dent Pract 12(3 Suppl):2-11

22. Kornman KS (2001) Patients are not equally susceptible to periodontitis: does this change dental practice and the dental curriculum? J Dent Educ 65(8):777-784

23. Roshna T, Nandakumar K (2012) Generalized aggressive periodontitis and its treatment options: case reports and review of the literature. Case Report Med 2012:535321

24. Heaton B, Dietrich T (2012) Causal theory and the etiology of periodontal diseases. Periodontol 2000 58(1):26-36

25. Diehl SR, Wu T, Burmeister JA, Califano JV, Brooks CN, Tew JG, Schenkein HA (2003) Evidence of a substantial genetic basis for lgG2 levels in families with aggressive periodontitis. J Dent Res 82(9):708-712

26. Michalowicz BS, Diehl SR, Gunsolley JC, Sparks BS, Brooks CN, Koertge TE, Califano JV, Burmeister JA, Schenkein HA (2000) Evidence of a substantial genetic basis for risk of adult periodontitis. J Periodontol 71(11):1699-1707

27. Adriaens PA, De Boever JA, Loesche WJ (1988) Bacterial invasion in root cementum and radicular dentin of periodontally diseased teeth in humans. A reservoir of periodontopathic bacteria. J Periodontol 59(4):222-230

28. Kishen A, Kumar GV, Chen NN (2004) Stress-strain response in human dentine: rethinking fracture predilection in postcore restored teeth. Dent Traumatol 20(2):90-100

29. Lang H, Korkmaz Y, Schneider K, Raab WH (2006) Impact of endodontic treatments on the rigidity of the root. J Dent Res 85(4):364-368

30. Ni CW, Chang CH, Chen TY, Chuang SF (2011) A multiparametric evaluation of post-restored teeth with simulated bone loss. J Mech Behav Biomed Mater 4(3):322-330

31. Scotti N, Scansetti M, Rota R, Pera F, Pasqualini D, Berutti E (2011) The effect of the post length and cusp coverage on the cycling and static load of endodontically treated maxillary premolars. Clin Oral Investig 15(6):923-929

32. Ferrari M, Cagidiaco MC, Grandini S, De Sanctis M, Goracci C (2007) Post placement affects survival of endodontically treated premolars. J Dent Res 86(8):729-734

33. Mazzitelli C, Monticelli F, Toledano M, Ferrari M, Osorio R (2012) Effect of thermal cycling on the bond strength of self-adhesive cements to fiber posts. Clin Oral Investig 16(3):909-915

34. Breschi L, Mazzoni A, Ruggeri A, Cadenaro M, Di Lenarda R, De Stefano Dorigo E (2008) Dental adhesion review: aging and stability of the bonded interface. Dent Mater 24(1):90-101

35. Van Landuyt KL, Snauwaert J, De Munck J, Peumans M, Yoshida Y, Poitevin A, Coutinho E, Suzuki K, Lambrechts P, Van Meerbeek B (2007) Systematic review of the chemical composition of contemporary dental adhesives. Biomaterials 28(26):3757-3785

36. Dimitrouli M, Geurtsen W, Luhrs AK (2012) Comparison of the push-out strength of two fiber post systems dependent on different types of resin cements. Clin Oral Investig 16(3):899-908

37. Radovic I, Monticelli F, Goracci C, Vulicevic ZR, Ferrari M (2008) Self-adhesive resin cements: a literature review. J Adhes Dent 10(4):251-258

38. Calixto LR, Bandeca MC, Clavijo V, Andrade MF, Vaz LG, Campos EA (2012) Effect of resin cement system and root region on the push-out bond strength of a translucent fiber post. Oper Dent 37(1):80-86

39. Gerth HU, Dammaschke T, Zuchner H, Schafer E (2006) Chemical analysis and bonding reaction of RelyX Unicem and Bifix composites-a comparative study. Dent Mater 22(10):934-941

40. Van der Reijden WA, Dellemijn-Kippuw N, Stijne-van Nes AM, de Soet JJ, van Winkelhoff AJ (2001) Mutans streptococci in subgingival plaque of treated and untreated patients with periodontitis. J Clin Periodontol 28(7):686-691

41. Tao L, Pashley D (1989) The relationship between dentin bond strengths and dentin permeability. Dent Mater 5(2):133-139

42. Vire DE (1991) Failure of endodontically treated teeth: classification and evaluation. J Endod 17(7):338-342

43. Komada W, Miura H, Okada D, Yoshida K (2006) Study on the fracture strength of root reconstructed with post and core: alveolar bone resorbed case. Dent Mater J 25(1):177-182

44. Naumann M, Rosentritt M, Preuss A, Dietrich T (2006) The effect of alveolar bone loss on the load capability of restored endodontically treated teeth: a comparative in vitro study. J Dent 34(10):790-795

45. Reinhardt RA, Krejci RF, Pao YC, Stannard JG (1983) Dentin stresses in post-reconstructed teeth with diminishing bone support. J Dent Res 62(9):1002-1008

10.1186/2196-4351-2-11

Cite this article as: Sales et al.: Effect of periodontal disease on the bond strength of fiber post cemented with different adhesive systems and resin luting agents. Applied Adhesion Science 2014, 2:11 